\title{
Numerical Study of the Interaction between a Reinforced Concrete Pile and Soil
}

\author{
N. M. Nde', D. Fokwa1, M. Mbessa ${ }^{2}$, T. T. Tamo², C. Pettang',3 \\ ${ }^{1}$ Department of Civil Engineering, University of Douala, Douala, Cameroon \\ ${ }^{2}$ Department of Civil Engineering, University of Yaoundé, Yaoundé, Cameroon \\ ${ }^{3}$ Department of Civil Engineering, University of Bamenda, Douala, Cameroon \\ Email: martialnde@yahoo.fr
}

How to cite this paper: Nde, N.M., Fokwa, D., Mbessa, M., Tamo, T.T. and Pettang, C. (2020) Numerical Study of the Interaction between a Reinforced Concrete Pile and Soil. Open Journal of Civil Engineering, 10, 259-269.

https://doi.org/10.4236/ojce.2020.103022

Received: May 15, 2020

Accepted: September 8, 2020

Published: September 11, 2020

Copyright $\odot 2020$ by author(s) and Scientific Research Publishing Inc. This work is licensed under the Creative Commons Attribution International License (CC BY 4.0).

http://creativecommons.org/licenses/by/4.0/

\begin{abstract}
This paper proposes a numerical simulation of the mechanical behavior of a reinforced concrete pile foundation under an axial load. In fact, the foundation of a structure represents the essential structural part of it, because it ensures its bearing capacity. Among the types of foundation, deep foundation is the one for which from a mechanical point of view, the justification takes into account the isolated or combined effects of base resistance offered by the soil bed and lateral friction at the soil-pile interface; the latter being the consequence of a large contact surface with the surrounding soil; hence the need to study the interaction between the soil and the pile in service, in order to highlight the characteristics of soil which influence the mechanical behavior of pile and therefore the stability of the structure. In this study, the reinforced concrete pile is supposed to be elastic, and characterized by a young's modulus $(E)$ and a Poisson's ratio $(v)$. The soil obeys to a Camclay model characterized by a cohesion $(c)$, an initial voids ratio $\left(e_{0}\right)$, shearing resistance angle $(\varphi)$ and a pre-consolidation pressure $\left(P_{0}\right)$. A joint model with a Mohr Coulomb behavior characterizes the soil-pile interface. The loading is carrying out by imposing a vertical monotonic displacement at the head of pile. The results in terms of stress and displacement show that the bearing capacity of the pile is influenced by various soils characteristics, it appears that the vertical stress and the force mobilized at rupture increase when the initial pre_consolidation pressure, the cohesion and the internal friction angle of soil increase; and when the initial soil voids index decreases.
\end{abstract}

\section{Keywords}

Pile, Soil, Interaction, Numerical Simulation, Pre_Consolidation Pressure, Voids Ratio, Cohesion, Internal Friction Angle 


\section{Introduction}

The foundation is the interface between the structure and the soil. It aims to distribute the weight of the structure over a large area in order to avoid of the soil plasticization, to anchor the structure against horizontal forces, to prevent lateral and vertical movements of the structure. There are two types of reinforced concrete foundation: the shadow and deep foundation. The first class of foundation is embedded at a deep less than two meters and is used when the soil at this level has good properties to avoid mechanical overstress and inadmissible settlement. The second one is used when the conditions of the shadow foundation are not satisfied. In this case, the level of the appropriate soil is deeper. It consists of a pile embedded in the soil with a length, which can vary from three to more than fifty meters depending on the project. The bearing capacity of the pile depends on its diameter, its length together with lateral friction between the soil and the pile, and the base resistance offered by the soil bed. The aim of the present paper is to analyze the interaction between a reinforced concrete pile and the soil in which it is embedded. Several studies have been carried out in this area, especially to highlight the influence of soil characteristics on pile behavior. Kavitha and others [1] show that in the soil-structure interaction analysis, the characteristics of soil has a very important role, the behavior of soil is predicted based on the engineering properties of soil (such as unit weight $(\gamma)$, shear modulus $\left(E_{s}\right)$, poisson's ratio $(v)$, shearing resistance angle $(\varphi)$, effective cohesion $(c)$ and angle of dilatancy $(\psi)$ ); vertical soil profile and the alignment of ground surface. Similarly, Abbas and others [2] found high effects of soil strength parameters (such as cohesion intercept c', modulus elasticity) on the pile behavior, they show that Pile with a low value of modulus elasticity of the soil settles higher and more critical than the pile with a high value of modulus elasticity of the soil; also, soil with low cohesion leads to significant pile settlements. In the same perspective, Khodair and Abde-Mohti [3] varied the modulus of elasticity of the clay, to study the effect of the stiffness of the soil (soft to hard clay) under a lateral deformation of $2 \mathrm{~cm}$ and show that at smaller or greater magnitudes of the modulus of elasticity, the discrepancy between the magnitude of the bending moments and lateral displacements increases due to adopting different clay stiffness in Abaqus/Cae and LPILE which is always based on a stiff clay definition for the soil. Mehrab and others [4] show that for piles with identical lengths, increasing soil density increases the critical buckling load of pile in both fully and partially embedded cases. They explain it by the existence of more confinement of the pile and consequently more resisting forces against displacement in denser soil. Al-Jazaairry and Toma-Sabbagh [5] show that Cavity presence near piles generates a reduction in the ultimate capacity depending on the location and size of the cavity. This work will study the influence of soils characteristics not taken into account by the previous ones, in particular the initial pre-consolidation pressure, the initial void index, the cohesion and the internal friction angle; knowing that these characteristics are decisive for structure construction on un- 
dergoing training sols. To achieve this, a physical model and mesh of soil-pile complex are presented, the mechanical behavior of soil, pile and soil-pile interface is given together with boundaries conditions of the problem, and the load by imposed displacement is applied at the head of the pile.

\section{Materials and Methods}

The study of mechanical behavior of pile subjected to monotonous axial loading will be done with CASTEM, 2017 version, developed by CEA Saclay in DEN/DM2S/SEMT. This code has as particularity the fact that it makes use of an object-oriented meta-language called "GIBIANE". The method is based on finites elements. It is considered as the most powerful tool in numerical modeling of soil-structure interaction, because of several advantage as: the possibility of using different boundaries conditions and combine loading, the versatility of the method which allows for modeling different pile and soil geometries, the possibility of finding solutions at each element and node in the mesh thanks to discretization of model into small entities, possibility to model different types of soil models and various material behavior for pile, and the continuity of the soil behavior can be taken into account. The method consists in defining an optimal geometry and mesh, a model of mechanical behavior for each component of the geometry, initial and boundary conditions, and finally mechanical loading.

\subsection{Geometrical Model}

Figure 1(a) and Figure 1(b) show the various view of soil-pile system, and Figure 1 (c) shows the symmetrical representation of the system due to the symmetry of the problem. Since only two-dimensional analysis will be considered here, the mesh will be done only in the $(\mathrm{x}, \mathrm{z})$ plan. The soil is considered as a homogeneous, isotropic and infinite mass in the $\mathrm{z}$ direction perpendicular to the $(\mathrm{x}, \mathrm{z})$ plane. The dimensions of the involved soil are $5 \mathrm{~m}$ in the $\mathrm{x}$ and $\mathrm{y}$ directions and $12 \mathrm{~m}$ in the $\mathrm{z}$ direction. The pile has a radius $0.3 \mathrm{~m}$ and $6 \mathrm{~m}$ length.

\subsection{Mesh}

The finite elements chosen are tri6 according to CASTEM software that means:

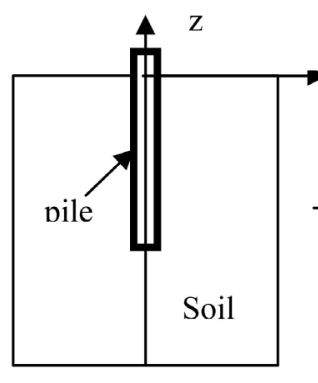

(a)

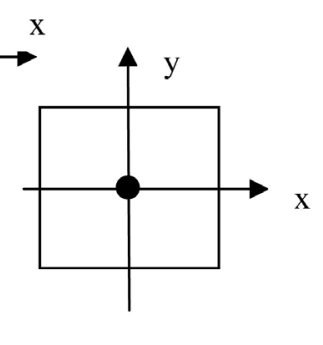

(b)

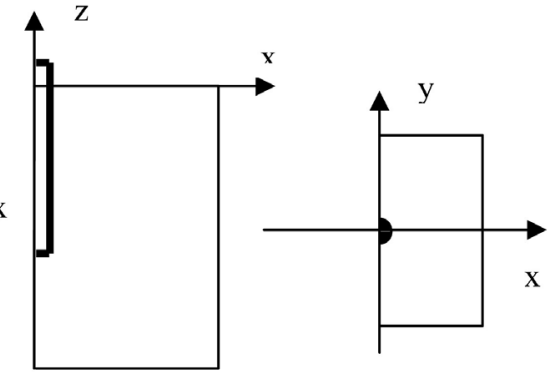

(c)

Figure 1. Geometrical model of the problem: (a) System in the $x-z$ plan; (b) System in the $\mathrm{x}-\mathrm{y}$ plan; (c) Partial representation due to the symmetry of the problem. 
triangle with 6 nodes and 2 degrees of freedom per node (UX; UY), for the meshes of the soil and the pile. The resolution being performed at the nodes of the mesh, it thus makes it possible to densify the node in the geometric model and to approach as well as possible the real solution. The mesh is narrowed in the soil-pile contact zone as shown in Figure 2, since this area is subject to significant stress transfer between the pile and the ground. The soil-pile interface is taken as joint element without thickness, the mesh of this one is ensured by finite element connected to $(2 \times 3)$ nodes $(\operatorname{rac} 3)$ and with 2 degrees of freedom per node (UX; UY).

\subsection{Behaviors' Models of the Components Soil, Pile and Interface}

\subsubsection{Modified Cam_Clay Model for Soil}

The soil has and elastoplastic behavior with modified Camclay's plasticity criterion. This behavior model is based on two concepts, limit sate and critical state. It postulates the existence of a limit state curve and a critical state to describe the elastoplastic behavior with isotropic hardening of soils normally consolidated, under homogeneous solicitations [6]. Roscoe and Burland [7] write the load function $F$ in the $(p, q)$ plane of this criterion by Equation (1).

$$
F(\sigma)=q^{2}+M^{2}\left(P^{\prime 2}-P^{\prime} P_{c}^{\prime}\right)
$$

$P^{\prime}$ and $q$ represent the spherical and deviatoric parts of the stress tensor; and $P_{c}^{\prime}$ the pre-consolidation pressure given according to Khemissa [8], by Equation (2), Equation (3) and Equation (4).

$$
\begin{gathered}
q=\sqrt{\left(\left(\sigma_{1}-\sigma_{2}\right)^{2}+\left(\sigma_{1}-\sigma_{3}\right)^{2}+\left(\sigma_{2}-\sigma_{3}\right)^{2}\right) / 2} \\
P^{\prime}=\operatorname{trace}[\bar{\sigma}] \\
P_{c}^{\prime}=P_{c 0}^{\prime} \exp \left[\left(\left(1+e_{i}\right) /(\lambda-k)\right) \varepsilon_{v}^{p}\right]
\end{gathered}
$$
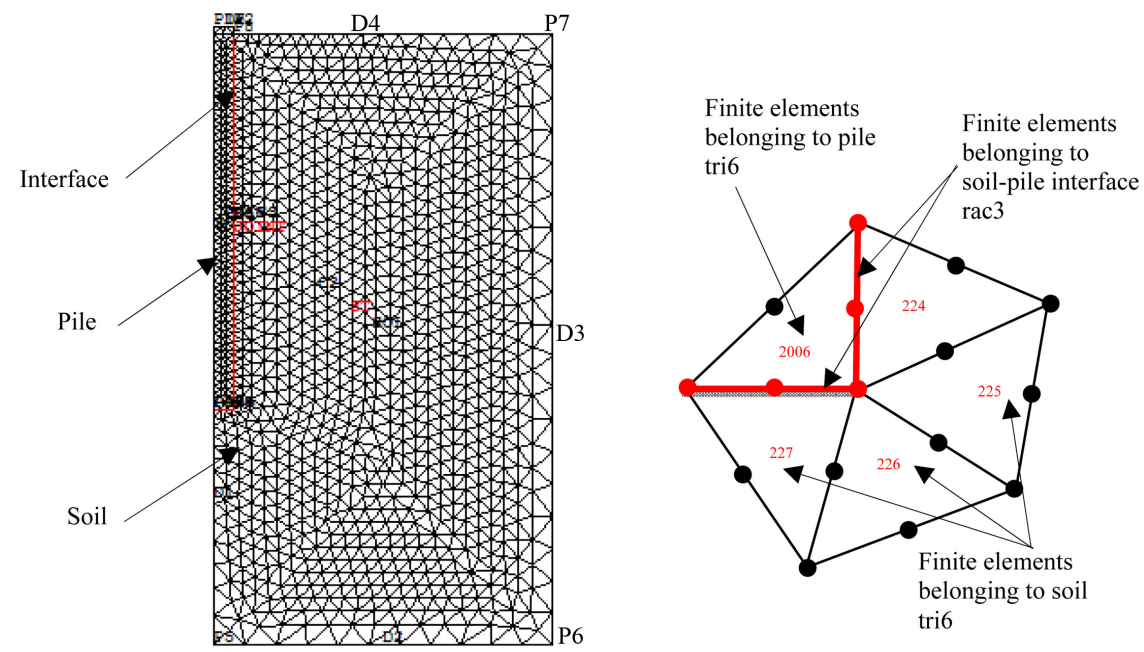

Figure 2. Discretization and mesh detail at the pile-soil interface. 
$e_{i}$ represents the initial voids ratio of soil (which is replaced by the ratio of preexisting voids $e_{0}$ for structural computations). $P_{c 0}^{\prime}$ is the initial pre-consolidation pressure, $\lambda$ the slope of the loading curve for a normally consolidated state and $k$ the slope of the unloading-reloading curve for an over-consolidated state. $\varepsilon_{v}^{p}$ the plastic components of strain. The slope of the critical state line $M$ in the $\left(p^{\prime}, q\right)$ plane or the coefficient of friction defined by Equation (5), where $M$ is the ratio of the stress deviator $q$ to the mean effective stress $p^{\prime}$ at the critical state. It is determined by a triaxial compression test and defined by Equation (6), according to Roscoe and Burland [7].

$$
q=M P^{\prime}
$$

$M$ is also the line representing the critical shear behavior of the soil, where the deformations continue to develop without changing the state of stress.

$$
M=6 \sin \varphi /(1-\sin \varphi)
$$

$\varphi$ is the internal friction angle of the soil.

The elastic law associated with this criterion is charactarized by the Young modulus $E$, and the poisson's ratio $v$ (assumed constant). They are taken into account by non-linear volumic compressibility $K$ and shear modulus $G$, given according to Roscoe and Burland [7] by Equation (8) and Equation (9).

$$
\begin{gathered}
K=\left(\left(1+e_{i}\right) / k\right) P^{\prime} \\
G=[3(1-2 v) / 2(1+v)] K
\end{gathered}
$$

The numerical values associated to CamClay model parameters are taken into account as in Khemissa's study [6].

\subsubsection{Elastic Model for the Pile}

The pile is considered very rigid with respect to the ground; it follows an isotropic linear elastic constitutive law, of constant parameters, defined by Equation (10).

$$
\sigma=E \cdot \varepsilon
$$

With $E$ the Young's modulus, $\varepsilon$ the strain andothe stress.

\subsubsection{Mohr Coulomb Plastic Model for the Soil-Pile Interface}

The zero-thickness element approach was used to model the joint at the soil-pile interface. This element follows the elastoplastic constitutive law, with Mohr-Coulomb's plasticity criterion and associated flow (Coulomb model implemented in CASTEM). The scalar function associated with this model is given by the load function $\mathrm{f}$ such that:

$$
f\left(\sigma_{n}, \tau\right)=|\tau|-\sigma_{n} \operatorname{tg} \phi+c
$$

With $\mathcal{c}, \varphi$, respectively the cohesion and the internal friction angle at the soil-pile interface. $\sigma_{n}$ and $\tau$ the normal and shear stress.

\subsection{Boundaries Conditions of Soil-Pile System}

Mechanical blockages are applied to the soil and pile geometries as shown in 
Figure 3. Thus, the boundary conditions concern the horizontal displacements (Ux) which are canceled on the lateral edges of soil (lines D1 and D3), as well as the vertical (Uz) and horizontal (Ux) displacements at the base of soil (lines D2). In order to prevent radial expansion of pile, zero displacement is applied in the (ox) direction ( $U x=0$ for pile). In addition, a mechanical blocking required for loading by imposed displacement of the structure was applied at the pile head, along the (oz) axis.

\subsection{Loading by Imposed Displacement at the Head of Pile}

Assuming that the embodiment of the concrete pile is not taken into account, the loading of the structure takes place at the pile head as shown in Figure 4(a), by imposed displacements $\mathrm{Uz}$, thus making it possible to simulate the behavior of the latter in a state of service. This imposed displacement will have the effect of creating shear forces at the soil-pile interface, as well as the settlement of the soil at the base of the pile; it will be shown that the amplitude of these two phenomena and their effects on the mechanical behavior of the pile depends on soil characteristics.

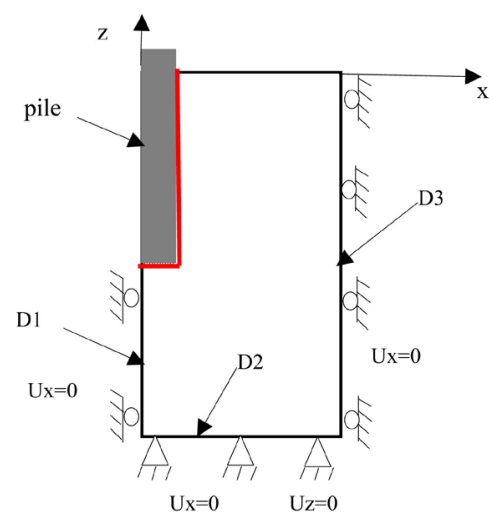

Figure 3. Boundaries conditions on soil-pile system.

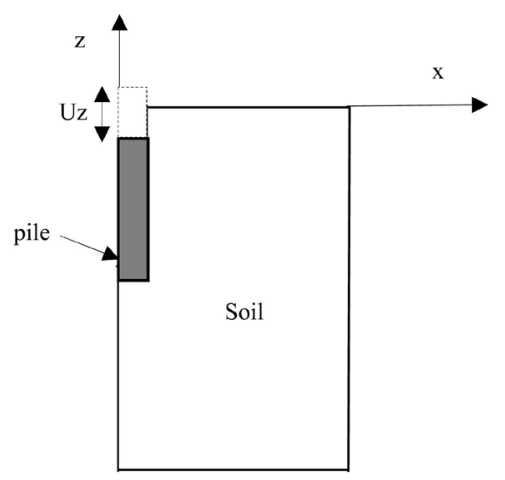

(a)

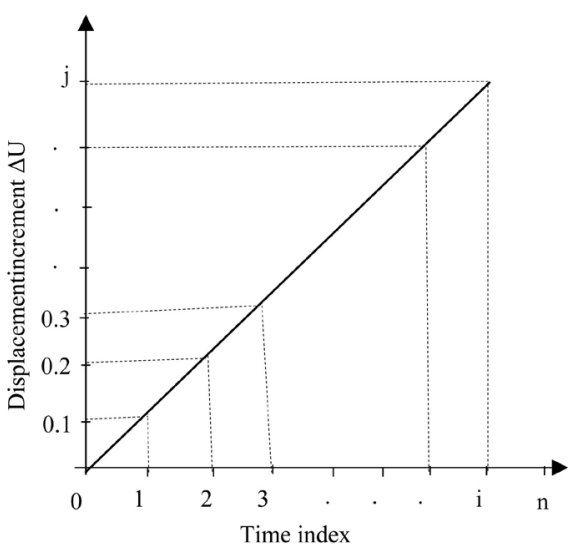

(b)

Figure 4. Loading; (a) displacement imposed at head of pile; (b) monotonic curve of displacement increment as function of time index. 
Since the computation is stepwise, the displacement increment is defined by a monotonic curve as a function of the increment of time shown in Figure 4(b). Thus, the loading is defined by the Equation (12).

$$
U_{i+1}=U_{i}+\Delta U
$$

where $\Delta U$ is the displacement increment, following a monotonic curve; $U_{i+1}$ displacement imposed at $i+1$ time index and $U_{i+1}$ displacement imposed at $i$ time index.

\section{Results and Discussions}

The finite element calculation will be done step by step using the dgibi programming language of CASTEM. The results will be extracted at the nodes and elements of the mesh as located in Figure 5.

In order to highlight the influence of soil characteristics on mechanical pile behavior, graphs of Figures 6-11 respectively show the stress-displacement curves at the head of the pile and the overall force-displacement of the pile; these curves are qualitatively consistent with the results of Roméo Francis [8], who conducted experiments on micro-pile models in a calibration room, in order to study their mechanical behavior; Shakhirev and other [9], then Balachowski and Dembicki's results on the study of pile models in a calibration room [10]; Jenck's results on the reinforcement of compressible soils by rigid vertical inclusion [11] and Foray's results on bearing capacity of model pile driven into over-consolidated sand [12].

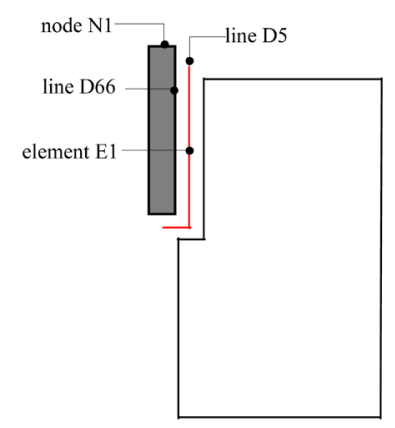

Figure 5. Locating nodes and elements for extracting results and plotting curves.

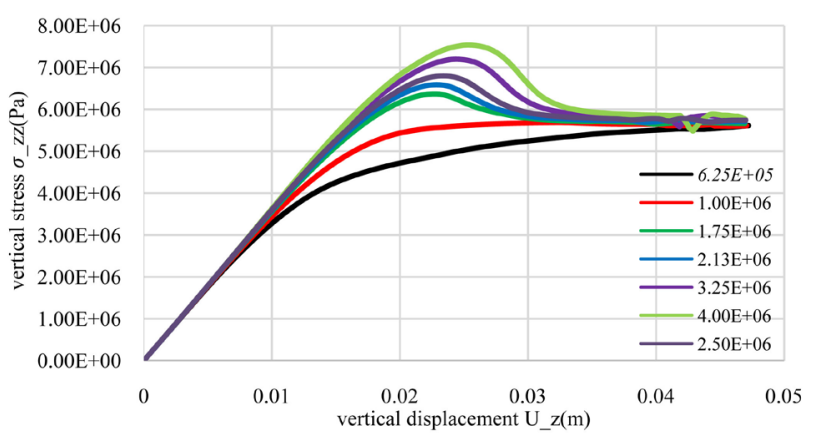

Figure 6. Stress-displacement at the head of the pile according to the pre-consolidation pressure. 


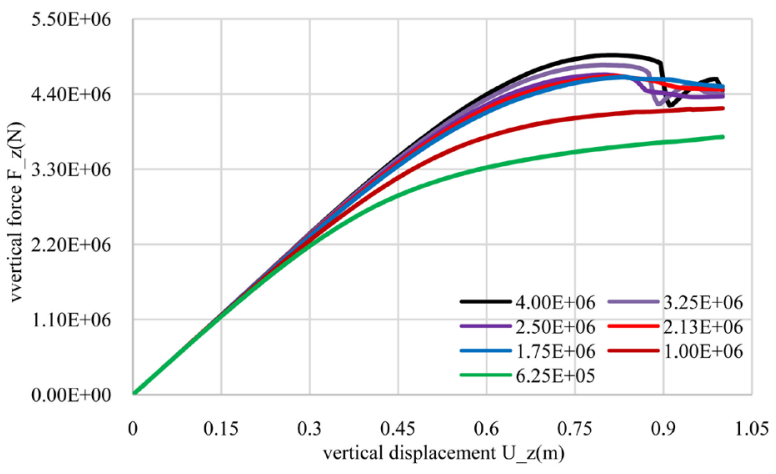

Figure 7. Overall force-displacement of the pile according to the pre-consolidation pressure.

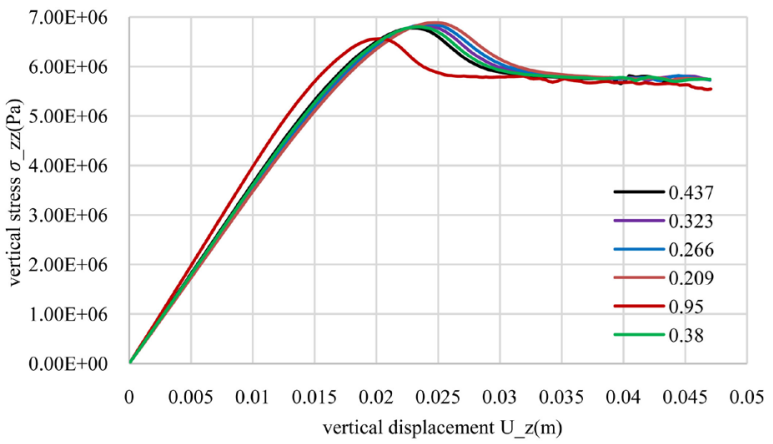

Figure 8. Stress-displacement at the head of the pile according to the voids ratio of soil.

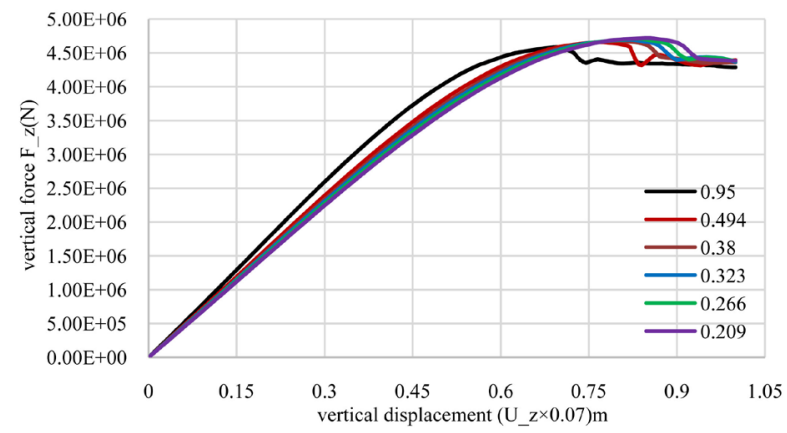

Figure 9. Overall force-displacement of the pile according to the voids ratio of soil.

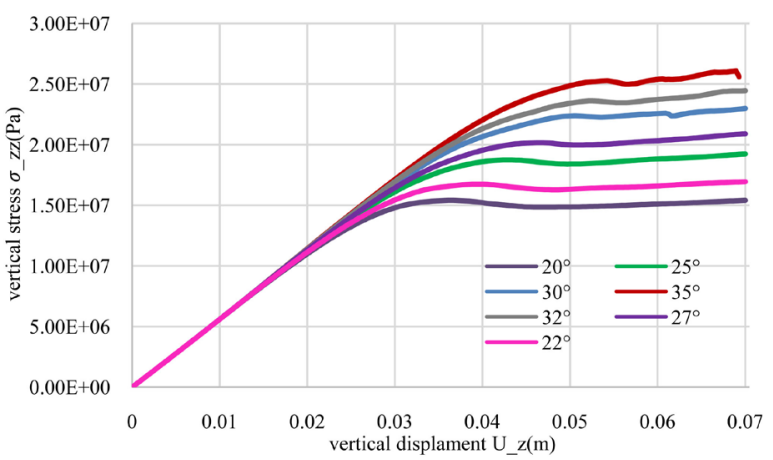

Figure 10. Stress-displacement at the head of the pile according to the angle of internal friction. 


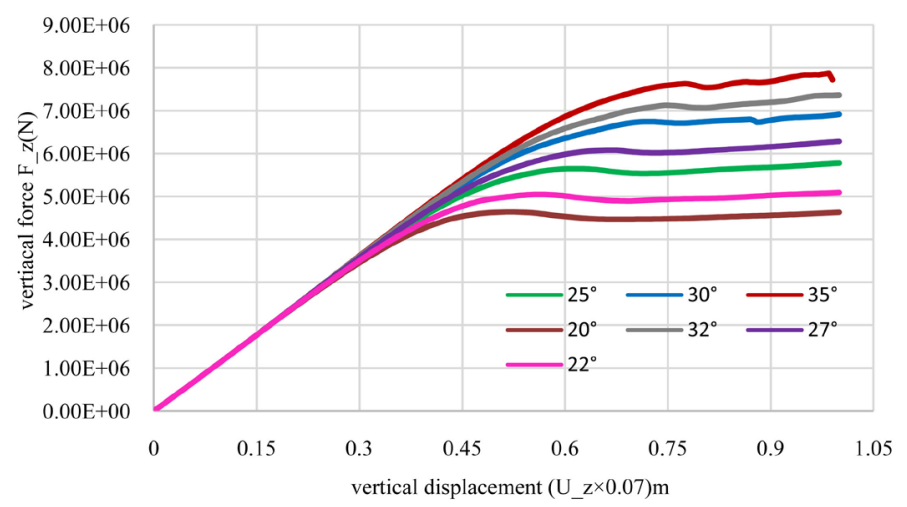

Figure 11. Overall force-displacement of the pile according to the angle of internal friction.

\subsection{Influence of Pre-Consolidation Pressure}

The evolutions of graphs of Figure 6 are qualitatively identical in the elastic zone (zone of small displacements), and all converge towards the same bearing characterizing the plastic flow at break. However, stress peaks increase with the initial pre-consolidation stress, thus characterizing soils in a more dense state. The mobilized stress and breaking force therefore increases when the initial pre-consolidation pressure is higher. Indeed, the dilatancy phenomenon that leads to the stress peak causes strain hardening of the soil, which is taken into account in the cam_clay model by Equation (4), in which the initial pre-consolidation pressure occurs. Taking this parameter into account during the design of the piles thus makes it possible to optimize the mobilized force at break, as shown in Figure 7.

\subsection{Influence of Initial Void Ratio}

Graphs of Figure 8 and Figure 9 present qualitatively similar evolutions; however, there are slight localized differences mainly in the area preceding the break. Indeed, these evolutions show that the initial voids ratio of soil has a weak influence on the mechanical behavior of the pile before the rupture of the ground. Thus, as the void ratio decreases, the stress at break is greater as shown in Figure 8. This can be explained by the fact that a lower void ratio implies a denser soil (high density index), thus able to mobilize a greater force at break as shown in Figure 9.

\subsection{Influence of Cohesion and Internal Friction Angle of Soil}

The evolutions of the graphs as shown in Figure 10 and Figure 11, are qualitatively and quantitatively identical in the elastic zone and all converge towards bearings limit characterizing the plastic flows at break. However, these bearings have higher tensile strengths as the angle of internal friction $\varphi$ and the soil cohesion increase $c$. The stress as well as the bearing capacity force increase with the cohesion and the angle of friction of the ground. Indeed, this last parameter is 
taken into account by the friction coefficient in Equation (6); the value of this coefficient increases with the internal friction angle, and in the same order of magnitude, increases the strain deflector leading to the shear of the soil.

\section{Conclusion}

The numerical study of the mechanical behavior of a pile subjected to a monotonous axial loading was proposed in this paper, using the finite element method via CASTEM software. The influence of soil characteristics on the mechanical behavior of the pile in service has been highlighted, and it appears that the vertical stress and the force mobilized at rupture increase when the initial pre_consolidation pressure, cohesion and the angle of friction of soil increase; and when the initial soil voids ratio decreases. These results are important in the design and realization of piles, to ensure a good bearing capacity of the pile, and therefore a better resistance and stability of the structures.

\section{Conflicts of Interest}

The authors declare no conflicts of interest regarding the publication of this paper.

\section{References}

[1] Kavitha, P.E., Beena, K.S. and Narayanan, K.P. (2016) A Review on Soil-Structure Interaction Analysis of Laterally Loaded Pile. Springer International Publishing Switzerland. https://doi.org/10.1007/s41062-016-0015-X

[2] Abbas, J.M., Abbas, A.L. and Abbas, M.A. (2012) The Axial Performance of Deep Foundation. European Journal of Scientific Research, 74, 574-582.

[3] Khodair, Y. and Abde-Mohti, A. (2014) Numerical Analysis of Pile-Soil Interaction under Axial and Lateral Loads. The International Journal of Concrete Structures and Materials, 8, 239-249. https://doi.org/10.1007/s40069-014-0075-2

[4] Mehrab, J., Seyede, H.N. and Mehrab, K. (2014) Numerical Analysis of Buckling Behavior of Concrete Pile under Axial Load Embedded in Sand. Arabian Journal for Science and Enginee, 39, 2683-2693. https://doi.org/10.1007/s13369-014-0970-5

[5] Al-Jazaairry, A.A. and Toma-Sabbagh, T.M. (2017) Performance of Axially Loaded Single Pile Embedded in Cohesive Soil with Cavities. International Journal of Environmental, Chemical, Ecological, Geological and Geophysical Engineering, 11, 558-562.

[6] Khemissa, M. (2004) Comparaison de deux modèlè pour l'analyse de la convergence des tunnels. Université Mohamad Boudiaf de M’sila, Algérie, 13 p.

[7] Roscoe, K.H. and Burland A.N. (1968) On the Generalized Behaviour of "Wet" Clay. In: Heyman, J. and Leckie, F., Eds., Cambridge University Press, London, 535-609.

[8] Francis, R. (1997) Etude du comportement mécanique de micropieux modèles en chambre d'étalonnage: Application aux effets de groupe, Ecole des Ponts et Chaussées.

[9] Shakhirev, V., Magnan, J.P. and Ejjaouani, H. (1996) Etude expérimentale du comportement de sol lors du fonçage des pieux. Bulletin des Laboratoires des Ponts et Chaussées, 206, 95-116. 
[10] Balachowski, L. and Dembicki, E. (2002) Une étude de pieux foncés dans une chambre d'étalonnage. Journées Nationales de Géotechnique et de Géologie, Nancy.

[11] Jenck, O. (2005) Le renforcement des sols compressibles par inclusion rigides verticales: Modélisation physique et numérique, INSA de Lyon.

[12] Foray, P., Balachowski, L. and Colliat, J.L. (2011) Bearing Capacity of Model Pile Driven into Overconsolidated Sand. Canadian Geotechnical Journal, 35, 374-385. 